\title{
Listeria monocytogenes outbreak in Europe - updates in 2018
}

\author{
Irina lanache ${ }^{1}$, Emanoil Ceausu ${ }^{1,2}$ \\ 1"Victor Babes" Hospital for Infectious and Tropical Diseases, Bucharest \\ 2"Carol Davila" University of Medicine and Pharmacy, Bucharest
}

\begin{abstract}
Listeria monocytogenes is the pathogen responsible for one of the most common zoonosis spread through contaminated food. It is characterized by a high capacity to withstand poor environmental conditions and to form biofilm. In general population it is most often a food-born infection, but it affects especially pregnant women, newborns, elderly and immunosuppressed persons, causing meningoencephalitis in these patients, and rarely, cardiac or osteoarticular conditions etc.

Over time, both sporadic and outbreaks with broad geographic distribution have been described in Africa, Europe, or in the United States of America. Over the last 3 years, Europe has faced an increased number of cases of listeriosis, spread due to frozen vegetables (especially corn). Using molecular tests, serotype IVb with the ST6 multilocular sequence was identified as prevalent during this outbreak.

The contamination source is a Hungarian company that packed and sold frozen vegetables on the market. The infectious strain persisted despite cleansing and disinfection measures. It was subsequently spread to other European Union (EU) countries. Even if the frozen vegetables were largely distributed in Europe (including Romania), and the strain was isolated in more countries, human listerios linked to these strains were registered only in 5 states.

Considerable efforts are being made in order to try to stop the spread of this outbreak by improving the hygiene, disinfection and control measures, and by withdrawing potentially contaminated products from the market.
\end{abstract}

Keywords: Listeria monocytogenes, outbreak, serotype IVbST6, frozen corn

\section{Lysteria monocitogenes - clinico-epidemiological, bacteriological and treatment characteristics}

Listeriosis is considered to be one of the most aggressive zoonosis, with oral spread, due to contaminated food. Even if not very frequent (with an incidence of $0.47 / 100.000$ in 2016 in EU), this infection also associate high mortality rate $(16.1 \%$ in 2016) (1,2).

The pathogen responsible for this condition is Listeria monocytogenes - a gram positive non spore forming bacillus which can live in both aerobic and anaerobic environment, surviving even in extreme conditions due to its increased ability to form biofilm (high salinity, thermic or $\mathrm{pH}$ extremes, increased osmolality, contact with metal ions etc.) (2).
The genesis of the biofilm is related to the hydrophilic character of listeria and its capacity to reproduce despite low temperatures, gaining both adherence to the surfaces and resistance to disinfecting substances and procedures (3).

The bacteria are often found in refrigerators or in other places where food and natural, unprocessed aliments are stored (fresh dairy products, smoked fish, frozen vegetables, unpasteurized milk or semiprepared food) $(3,4)$.

Six strains of Listeria monocytogenes were described (J2-031, JO161, J2-064, R2-502, F2365, ScottA), with 12 serotypes, out of which only three $(1 / 2 a, 1 / 2 b, 4 b)$ are considered to be responsible for almost $95 \%$ of human listeriosis cases. $4 \mathrm{~b}$ serotype is most often isolated during outbreaks $(5,6)$. 
After contaminated food ingestion, listeria penetrates the intestinal mucosa entering the systemic circulation. Cell invasion is followed by the bacteria penetration in the cytosol, helped by listeriolysin $\mathrm{O}$ enzyme (LLO) and a series of phospholipases which form pores in the membrane. Subsequently, the actin assembly complex is activated, through which listeria moves intracellularly and spreads from one cell to another $(3,7)$.

Listeriosis is relatively rare in general population, affecting more frequently pregnant women, newborns and elderly (due to impaired humoral mediated immunity), as well as immunocompromised persons. It seems that HIV-infected patients and those diagnosed with hematological malignancies associate a high risk of listeriosis due to altered cell immunity. In case of pregnancy, listeria may also associate spontaneous abortion, intrauterine death, fetal malformations and even disseminated neonatal infections, despite antibiotic treatment $(8,9)$.

The incubation period usually varies between 3 and 70 days, with a median of 21 days. The most common symptoms are related to intestinal damage, the infection in immunocompetent patients often manifesting as an enterocolitis with fever, diarrhea, nausea and vomiting. Bacteremia and brain damage are more severe conditions, causing meningitis, meningoencephalitis or cerebral abscesses. Cases of endocarditis, septic arthritis, osteomyelitis or even pneumonia, were also reported (2,10-14).

The therapeutic management of listeriosis involves parenteral antibiotic with variable periods of administration, depending on the infection site. Ampicillin is the antibiotic of choice, while aminoglycosides (mainly gentamicin), are administered due to their synergic effect, but only for short periods of time (no longer than a week in order to avoid renal and ototoxicity). Trimethoprim-sulfamethoxazole is the most important alternative in case of allergy to ampicillin, but erythromycin, vancomycin, fluoroquinolones or linezolid can also be used, the last one having good brain penetration. Listeria monocytogenes is characterized by intrinsic resistance to cephalosporins (15-17).

Antibiotic treatment duration is approximatively 2 weeks in an immunocompetent patient with positive blood cultures. Longer treatment duration is necessary in case of immunosuppressed hosts, or in case of meningitis ( 3 weeks), cardiac conditions (4 weeks) or cerebral abscess (at least 6 weeks). Surgical approach was rarely described, being recommended in case of osteo-articular infections (several cases of joint prostheses infection in immunosuppressed patients were described) $(16,18)$.

\section{Listeria outbreaks - brief history}

Over time, listeriosis was diagnosed both as sporadic cases or outbreaks, associating a high hospitalization rate, with more than $90 \%$ patients being admitted to hospital. It is considered to be the zoonosis with the highest number of inpatients from Europe. Several outbreaks with Listeria monocytogenes were reported over time, with variable sources of infection $(2,9,19)$.

Listeriosis infections due to salads, unpasteurized milk and Mexican cheese were described in Canada, New England and California between 1980 and 1990. Later, at the end of last century, more European countries (France, Italy, Sweden and Switzerland), as well as other American states, also reported numerous cases of infections with Listeria monocytogenes due to dairy products, fish and meat. Since 2002, several listeriosis outbreaks were registered, most often in United States of America, but also in Great Britain, due to food based on milk, turkey breast, apples or sandwiches (20-24).

Almost all recent outbreaks (2013-2016) were reported in USA and the source of infection was considered to be the use of dairy products, meet, cheese, as for previously episodes, but also frozen vegetables, blue berry ice cream or caramelized apples $(19,25,26)$. Multiple infections, with low number of patients were identified during last years, due to the improvement of diagnostic tests. Listeriosis incidence reported in EU in 2013, registered a significant increase, with $8.6 \%$ compared to previous year. The incidence rate was $0.44 / 100.000$ persons, while the mortality rate was $15.6 \%$ from the total of confirmed reported cases. Seven outbreaks were reported in $5 \mathrm{EU}$ countries. In addition to diary and meat products, as well as vegetables, previously reported as being sources of infections, crustaceans, mollusks and shellfish were also incriminated as being responsible for these outbreaks $(19,27)$. 
Despite the decreasing number of listeriosis outbreaks related to meat products due to prevention measures implemented in food industry from United States, more cases of infection due to aliments considered to be with medium or low risk, like vegetables, fruits, salads or even ice cream, were described during last years $(19,25)$.

Due to all this outbreaks, it was concluded that the immune status of the patient, as well as the associated comorbidities and treatment, have often a much more important influence on the clinical evolution of the patient than the infective dose $(19,28)$.

\section{Listeria monocytogenes outbreak spread through frozen vegetables in Europe in 2015-2018}

Starting with 2015, it was observed an increasing number of patients newly diagnosed with listeriosis, most probably due to frozen vegetables (especially corn). During this outbreak, that has so far affected more European countries (Austria, Denmark, Finland, Sweden and Great Britain), 47 cases were reported, with a fatality rate of $19 \%$ (9 deaths). Median age at diagnosis was 72 years (IQR 56-86), more than half of the patients, 55\% (26/47) being females. The number of newly infections has progressively increased between 2015 and 2018, being higher in the first 6 months of 2018 (18) compared to previously years (17 in 2017, 11 in 2016 and 1 in 2015) (29).

Genomic sequencing revealed the strain of Listeria monocytogenes, serotype IVb, the multilocular sequence type 6 (ST6), as being responsible for these infections. This strain is characterized by hypervirulence and neurotropism, leading to cerebral involvement (29-31). The sequencing was performed for the first time in Finland, at the end of 2017. 14 more such strains were also described in this country between January 2016 and January 2018. Subsequent sequencing was performed in the other 4 EU countries affected by the outbreak and closely related strains to the initial one were identified, with differences of 0 to 7 allele (29).

Even if this strain was also isolated in frozen vegetables or cold storage rooms from other countries, like France, Belgium, Ireland, Germany, Italy, Portugal, Norway, Luxembourg or The Netherlands, there was no human listeriosis diagnosed in these states during this period. A high number of these strains, with no human infections associated, were isolated in 2017 (29).

Taking into consideration the fact that the strain responsible for the spread of this outbreak was isolated using genetic sequencing, and this technique is performed only in a few EU countries, it is very probable that the number of cases is underestimated (29).

South Africa is also facing a listeriosis outbreak starting in 2017, the source of infection being related to semi prepared meat products (sausages etc.). A total number of 1019 cases of infection with Listeria monocytogenes were confirmed in this region, between January 2017 and March 2018, with a fatality rate of $27 \%$. Even if subtype ST6 was also reported as being prevalent among African patients during this period, any possible link between the European and African outbreaks was excluded due to epidemiologic and molecular tests $(14,32,33)$.

The source of infection for the European outbreak was isolated in the cold storage rooms of a Hungarian company, where frozen vegetables responsible for these infections were stored. Because IVbST6 strain was isolated from both corn and other frozen vegetables (like spinach, green beans, etc.), it is thought that all of them were stored and processed in the same place, contaminated and therefore involved in the spread of the infection (29).

The actual outbreak was disseminated due to aliments marketed during last three years (2016, 2017, 2018), rising some questions about the strain resistance, despite disinfection procedures that were implemented. More than that, the use of contaminated frozen vegetables for food preparation, also favored the spread of the infection. It is considered that the risk of new cases of infection with L. monocytogenes IVb, ST6 still exists due to more factors. Examples include the fact that the last cases were recently diagnosed (May 2018), the frozen vegetables marketed by the Hungarian company are still in use (even if they have been withdrawn from the market and there were performed several campaigns through the consumers were advised to return the products purchased between 2016 and 2018), the incubation period is long (up to 70 days) and often the vegetables are not enough heated when cooked (29). 
In an attempt to diminish the spread of this infection, the activity of the Hungarian company has been diminished since June 2018, and states like Estonia, Finland, Poland or Sweden have withdrawn from the market corn and other frozen vegetables considered to have a potential risk in spreading the infection. Also, the procedures for cleaning and disinfecting all the equipment used during the processing and packaging of these foodstuffs and refrigeration chambers have been intensified and carefully monitored, as well as the hygiene measures adopted by staff and all operators involved in this process (29).

Even if the products marketed by the Hungarian company were also distributed in Romania, no case of human listeriosis linked to the actual European outbreak has been reported in our country. However, the prevention measures recommended in Eu- rope were also implemented, and the possible infected products were withdrawn from the Romanian market.

\section{CONCLUSIONS}

Listeriosis is an infection transmitted by contaminated food, most often affecting pregnant women, newborns, elderly and immunosuppressed patients in whom it frequently causes life threatening cerebral conditions. During the last three years, Europe had to face a new outbreak, frozen corn being identified as source of infection. The number of patients increased during last 6 months, suggesting that the source couldn't be controlled. The implementation of efficient prevention and control measures is still a priority in order to stop the spread of this infection.

\section{REFERENCES}

1. European Centre for Disease Prevention and Control (ECDC);. Surveillance Atlas of Infectious Diseases - Listeriosis: European centre for Diseases Prevention and Control; 2017. Available from: https://ecdc.europa.eu/en/surveillance-atlas-infectious-diseases.

2. Kurpas M., Wieczorek K., Osek J. Ready-to-eat Meat Products As a Source of Listeria Monocytogenes. Journal of veterinary research. 2018; 62(1):49-55.

3. Galie S., Garcia-Gutierrez C., Miguelez E.M., Villar C.J., Lombo F. Biofilms in the Food Industry: Health Aspects and Control Methods. Frontiers in microbiology. 2018; 9:898.

4. Gomez D., Azon E., Marco N., Carraminana J.J., Rota C., Arino A. et al. Antimicrobial resistance of Listeria monocytogenes and Listeria innocua from meat products and meat-processing environment. Food microbiology. 2014; 42:61-5.

5. Metz Z.P., Ding T., Baumler D.J. Using genome-scale metabolic models to compare serovars of the foodborne pathogen Listeria monocytogenes. PloS one. 2018; 13(6):e0198584.

6. Swaminathan B., Gerner-Smidt P. The epidemiology of human listeriosis. Microbes and infection. 2007; 9(10):1236-43.

7. Kanki M., Naruse H., Kawatsu K. Comparison of listeriolysin $O$ and phospholipases PlcA and PlcB activities, and initial intracellular growth capability among food and clinical strains of Listeria monocytogenes. Journal of applied microbiology. 2018; 124(3):899909.

8. Mook P., O'Brien S.J., Gillespie I.A. Concurrent conditions and human listeriosis, England, 1999-2009. Emerging infectious diseases. 2011; 17(1):38-43.

9. Montero D., Bodero M., Riveros G., Lapierre L., Gaggero A., Vidal R.M. et al. Molecular epidemiology and genetic diversity of Listeria monocytogenes isolates from a wide variety of ready-to-eat foods and their relationship to clinical strains from listeriosis outbreaks in Chile. Frontiers in microbiology. 2015; 6:384.

10. Ristori C.A., Rowlands R.E., Martins C.G., Barbosa M.L., Yoshida J.T., Franco B.D. Prevalence and populations of Listeria monocytogenes in meat products retailed in Sao Paulo, Brazil. Foodborne pathogens and disease. 2014; 11(12):969-73.

11. Siegman-Igra Y., Levin R., Weinberger M., Golan Y., Schwartz D., Samra Z. et al. Listeria monocytogenes infection in Israel and review of cases worldwide. Emerging infectious diseases. 2002; 8(3):305-10.

12. Goulet V., King L.A., Vaillant V., de Valk H. What is the incubation period for listeriosis? BMC infectious diseases. 2013; 13:11.

13. Ferreira V., Wiedmann M., Teixeira P., Stasiewicz M.J. Listeria monocytogenes persistence in food-associated environments: epidemiology, strain characteristics, and implications for public health. Journal of food protection. 2014; 77(1):150-70.

14. Allam M., Tau N., Smouse S.L., Mtshali P.S., Mnyameni F., Khumalo Z.T.H. et al. Whole-Genome Sequences of Listeria monocytogenes Sequence Type 6 Isolates Associated with a Large Foodborne Outbreak in South Africa, 2017 to 2018. Genome announcements. 2018; 6(25).

15. Temple M.E., Nahata M.C. Treatment of Listeriosis. Annals of Pharmacotherapy. 2000; 34(5):656-61.

16. Lorber B. Listeriosis. Clinical infectious diseases: An official publication of the Infectious Diseases Society of America. 1997; 24 (1):1-9; quiz 10-1.

17. Pagliano P., Arslan F., Ascione T. Epidemiology and treatment of the commonest form of listeriosis: meningitis and bacteraemia. Le infezioni in medicina: Rivista periodica di eziologia, epidemiologia, diagnostica, clinica e terapia delle patologie infettive. 2017; 25(3):210-6.

18. Charlier C., Leclercq A., Cazenave B., Desplaces N., Travier L., Cantinelli T. et al. Listeria monocytogenes-associated joint and bone infections: A study of 43 consecutive cases. Clinical infectious diseases: An official publication of the Infectious Diseases Society of America. 2012; 54(2):240-8.

19. Buchanan R.L., Gorris L.G.M., Hayman M.M., Jackson T.C., Whiting R.C. A review of Listeria monocytogenes: An update on outbreaks, virulence, dose-response, ecology, and risk assessments. Food Control. 2017; 75:1-13.

20. Linnan M.J., Mascola L., Lou X.D., Goulet V., May S., Salminen C. et al. Epidemic listeriosis associated with Mexican-style cheese. The New England journal of medicine. 1988;319(13):823-8.

21. Goulet V., Rocourt J., Rebiere I., Jacquet C., Moyse C., Dehaumont $\mathrm{P}$. et al. Listeriosis outbreak associated with the consumption of rillettes in France in 1993. The Journal of infectious diseases. 1998; 177(1):155-60.

22. Dalton C.B., Austin C.C., Sobel J., Hayes P.S., Bibb W.F., Graves L.M. et al. An outbreak of gastroenteritis and fever due to Listeria 
monocytogenes in milk. The New England journal of medicine. 1997; 336(2):100-5.

23. Gottlieb S.L., Newbern E.C., Griffin P.M., Graves L.M., Hoekstra R.M., Baker N.L. et al. Multistate outbreak of Listeriosis linked to turkey deli meat and subsequent changes in US regulatory policy. Clinical infectious diseases: An official publication of the Infectious Diseases Society of America. 2006; 42(1):29-36.

24. Hughey V.L., Wilger P.A., Johnson E.A. Antibacterial activity of hen egg white lysozyme against Listeria monocytogenes Scott A in foods. Applied and environmental microbiology. 1989; 55(3):631-8.

25. Cartwright E.J., Jackson K.A., Johnson S.D., Graves L.M., Silk B.J., Mahon B.E. Listeriosis outbreaks and associated food vehicles, United States, 1998-2008. Emerging infectious diseases. 2013; 19(1):1-9; quiz 184.

26. Pouillot R., Klontz K.C., Chen Y., Burall L.S., Macarisin D., Doyle M. et al. Infectious Dose of Listeria monocytogenes in Outbreak Linked to Ice Cream, United States, 2015. Emerging infectious diseases. 2016; 22(12):2113-9.

27. European Food Safety Authority (EFSA); European Centre for Disease Prevention and Control (ECDC). The European Union summary report on trends and sources of zoonoses, zoonotic agents and food-borne outbreaks in 2013 2016. Available from: https://efsa. onlinelibrary.wiley.com/doi/10.2903/j.efsa.2015.3991.

28. Rietberg K., Lloyd J., Melius B., Wyman P., Treadwell R., Olson G. et al. Outbreak of Listeria monocytogenes infections linked to a pasteurized ice cream product served to hospitalized patients. Epidemiology and infection. 2016; 144(13):2728-31.

29. European Centre for Disease Prevention and Control (ECDC). Multi-country outbreak of Listeria monocytogenes serogroup IVb, multi-locus sequence type 6 , infections linked to frozen corn and possibly to other frozen vegetables - first update ECDC2018 [updated 3 July 2018]. Available from: https://ecdc.europa.eu/sites/ portal/files/documents/2018_ECDC-EFSA_ROA_Update1_UI-444_ Listeria.pdf.

30. Maury M.M., Tsai Y.H., Charlier C., Touchon M., Chenal-Francisque V., Leclercq A. et al. Uncovering Listeria monocytogenes hypervirulence by harnessing its biodiversity. Nature genetics. 2016; 48(3):308-13.

31. Koopmans M.M., Brouwer M.C., Bijlsma M.W., Bovenkerk S., Keijzers W., van der Ende A. et al. Listeria monocytogenes sequence type 6 and increased rate of unfavorable outcome in meningitis: epidemiologic cohort study. Clinical infectious diseases: an official publication of the Infectious Diseases Society of America. 2013; 57(2):247-53.

32. European Centre for Disease Prevention and Control (ECDC); European Food Safety Authority (EFSA). Multi-country outbreak of Listeria monocytogenes serogroup IVb, multi-locus sequence type 6, infections probably linked to frozen corn - 22 March 20182018. Available from: https://ecdc.europa.eu/sites/portal/files/ documents/22-02-2018-RRA-Listeria-Finland.pdf.

33. Health Department Republic of South Africa (Africa DHRoS). Media statement by the Minister of Health Dr Aaron Motsoaledi regarding the update on the Listeriosis outbreak in South Africa 2018. Available from: http://www.kznhealth.gov.za/Listeriosis/Media-statementNDOH-04032018.pdf. 